\title{
Expression patterning reveals retinal inflammation as a minor factor in experimental retinopathy of ZDF rats
}

\author{
Paulus Wohlfart $\cdot$ Jihong Lin $\cdot$ Nadine Dietrich $\cdot$ \\ Aimo Kannt • Ralf Elvert • Andreas W. Herling • \\ Hans-Peter Hammes
}

Received: 21 August 2013/Accepted: 19 December 2013/Published online: 30 January 2014

(C) The Author(s) 2014. This article is published with open access at Springerlink.com

\begin{abstract}
Obese Zucker diabetic fatty (ZDF) rats are used as a type- 2 diabetes model for microvascular complications. In order to study retinopathy in this model, changes in retinal vasculature were analyzed by quantitative morphometry and related to retinal expression of 46 selected genes that were analyzed by microfluidic card PCR technology. At 3 months of age, obese animals had developed stable hyperglycemia $(20.7 \pm 1.3 \mathrm{mmol} / \mathrm{L}$ plasma glucose vs. $6.5 \pm 0.1 \mathrm{mmol} / \mathrm{L}$ in lean). Hyperinsulinemia initially presented in obese rats at 2 months $(10.5 \pm 0.7 \mu \mathrm{g} / \mathrm{L}$ plasma insulin vs. $0.2 \pm 0.04 \mu \mathrm{g} / \mathrm{L}$ in lean) and decreased at 3 months $(3.9 \pm 0.6$ vs. $0.5 \pm 0.09 \mu \mathrm{g} / \mathrm{ml}$ in lean). At 8 months of age, animals had developed microvascular complications. An increased number of acellular capillaries in obese $\left(24 \pm 5 / \mathrm{mm}^{2}\right)$ versus lean $\left(15 \pm 4 / \mathrm{mm}^{2}\right)$ and a decreased number of retinal pericytes in obese $\left(2,270 \pm 250 / \mathrm{mm}^{2}\right)$ versus lean animals $(1,620 \pm 243 /$ $\mathrm{mm}^{2}$ ) could be observed. VEGFa, MIF, and HIF- $1 \alpha$ were the most abundantly expressed and inflammatory genes such as TNF $\alpha$ and IL- 6 are the least abundantly expressed genes. None of these genes were differentially regulated. Surprisingly, specific growth factors such as bFGF (FGF2)
\end{abstract}

Communicated by Massimo Porta.

Electronic supplementary material The online version of this article (doi:10.1007/s00592-013-0550-2) contains supplementary material, which is available to authorized users.

P. Wohlfart $(\bowtie) \cdot$ A. Kannt $\cdot$ R. Elvert · A. W. Herling R\&D Diabetes Division, Research and Translational Medicine, Sanofi, Industriepark Höchst, 65926 Frankfurt, Germany e-mail: paulus.wohlfart@sanofi.com

J. Lin · N. Dietrich · H.-P. Hammes

5th Medical Department, Universitätsmedizin Mannheim

(UMM), University of Heidelberg, Mannheim, Germany and placental growth factor, and adhesion molecules such as ICAM-1 were abundantly expressed and up-regulated in diabetic versus non-diabetic ZDF rats. In summary, we observed in type-2 diabetic ZDF rats retinopathy with retinal vasoregression along with a simultaneous up-regulation of specific growth factors such as bFGF and adhesion molecules, but only minor changes in key inflammatory genes.

Keywords Zucker diabetic fatty rats - Diabetic retinopathy · Preclinical model - Growth factors . Inflammation · Adhesion

\section{Introduction}

Diabetic retinopathy is a major complication of diabetes and observed in nearly all individuals with type- 1 diabetes and in more than $80 \%$ of individuals with type- 2 diabetes after 20 years of disease. High glucose levels damage in particular the retina of diabetic patients and involve small vessel vasoregression and pericyte loss as initiating processes. However, although hyperglycemia is the most important single factor, it explains only partially the overall damage as indicated by results from large clinical trials [1].

Rodent animal models recapitulate incipient retinal damage, including vasoregression. However, most of the rodent models still build on chemical or genetically induced destruction of the pancreas, mimicking type-1 diabetes. Male obese Zucker diabetic fatty (ZDF) rats are a genetic model of type-2 diabetes, mostly used for the characterization of diabetic nephropathy, whereas retinopathy is described still incompletely. Danis and Yang demonstrated in retina of diabetic ZDF rats modestly increased numbers of cellular nuclei and an increased basement membrane thickness [2,3]. An increased number 
of retinal acellular capillaries (AC) and apoptotic pericytes and endothelial cells were identified in aged diabetic ZDF rats and partially reduced by long-term treatment with a tumor necrosis alpha (TNF $\alpha)$ scavenger [4]. TNF $\alpha$ also mediated diabetes increased translocation of FOXO1 to nuclei in microvascular cells in vivo [5]. Up-regulation of retinal expression of $\mathrm{TNF} \alpha$, but also other markers of inflammation could be demonstrated in 14-week-old obese versus lean $\mathrm{ZDF}$ rats [6].

Inflammation may be an important disease mechanism in diabetes, and obese ZDF rats develop local and systemic inflammation with increased levels of circulating inflammatory biomarkers and increased infiltration of CD11bpositive cells into adipose tissue [7]. In a pilot study, we noticed, however, that in the retina, the expression of TNF $\alpha$ and other inflammatory markers falls clearly below other interesting factors and hence may be overestimated. We therefore investigated in male aged obese ZDF rats and lean littermates retinal morphology and, in parallel, associated gene expression pattern by a novel method of parallel quantitative PCR in microfluidic cards. This technology enables accurate assessment of abundance over a wide dynamic range and, in parallel, regulation of genes of interest. We selected genes of interest from published sources with an emphasis on growth factors, inflammatory markers, and adhesion molecules.

\section{Methods}

Zucker diabetic fatty (ZDF-Lepr ${ }^{\mathrm{fa}} / \mathrm{Crl}$ ) rats were obtained from Charles River Laboratories (Brussels, Belgium) in two genotypes, obese ZDF (genotype $\mathrm{Fa} / \mathrm{Fa}$ ) and lean ZDF littermates (genotype $\mathrm{Fa} /$ ?) and kept under standard housing. The principles of laboratory animal care (NIH publication No. 86-23, revised 1985) were followed, as well as the specific national law (the current version of the German Law on the Protection of Animals) and further Sanofi internal guidelines where applicable. Eight animals per group were used in all subsequent analyses. Diabetes was monitored weekly by blood glucose and insulin, and body weight measurements.

Retinal preparation and quantification of morphometry

Retinal morphology was analyzed by retinal digest preparations and quantitative morphometry in 8-month-old ZDF rats as described [8]. Briefly, after fixation of eyes in $4 \%$ PBS-buffered formaldehyde solution for 2 days, retinae were isolated and then incubated with trypsin. Following a periodic acid-Schiff (PAS)-hematoxylin staining, the number of total pericytes was evaluated in ten randomly selected fields per retina under $400 \times$ magnification using an image system and Cell ${ }^{\mathrm{F}}$ analyzing software (Olympus, Hamburg, Germany). The cell numbers were normalized to relative capillary density (cell numbers $/ \mathrm{mm}^{2}$ capillary area). AC were counted under $40 \times$ objective with a sample of PAS-stained retinal vasculature and normalized to relative retinal area (AC numbers $/ \mathrm{mm}^{2}$ retinal area).

\section{Gene expression measurements}

Expression of several genes was quantified in parallel by using TaqMan microfluidic card technology on an Applied Biosystems ViiA7 cycler (software version 1.1). Retinal RNA was isolated from individual retinas homogenized in $1 \mathrm{ml}$ Trizol reagent (Invitrogen, Karlsruhe, Germany) according to the manufacturer's instructions. Crude RNA was repurified using a RNeasy Mini Kit (Qiagen, Hilden, Germany) followed by reverse transcription into cDNA using a high-capacity kit (Life technologies, Darmstadt, Germany). Samples were mixed with TaqMan Universal PCR Master Mix (Life technologies, Darmstadt, Germany). Ports of 384-well-format microfluidic cards were filled with $100 \mu \mathrm{l}$ sample solution, briefly centrifuged twice for 1,500X g, and sealed. Each 384-well microfluidic card contained the specific TaqMan primers to detect 48 genes (46 target genes and 2 housekeeping genes) for 16 samples per plate. TaqMan primers were selected as the best coverage for the specific genes, as recommended by the manufacturer. For reference gene normalization, eukaryotic 18S rRNA (Assay Hs99999901_s1) and beta-2microglobulin (B2 M, Rn00560865_m1) were selected. Those reference genes were not found regulated in pilot diabetes studies. In an initial step, the plate was heated to $95{ }^{\circ} \mathrm{C}\left(1{ }^{\circ} \mathrm{C} / \mathrm{s}\right.$ to $50 \mathrm{~min}$, then $50{ }^{\circ} \mathrm{C}$ for $2 \mathrm{~min}, 1{ }^{\circ} \mathrm{C} / \mathrm{s}$ to $95^{\circ} \mathrm{C}$, then $95{ }^{\circ} \mathrm{C}$ for $\left.10 \mathrm{~min}\right)$. Subsequently, a real-time PCR was performed with a maximum of 40 cycles each consisting of sub-step $1\left(95{ }^{\circ} \mathrm{C}\right.$ for $15 \mathrm{~s}$, rapid cooling to $60{ }^{\circ} \mathrm{C}$ with $\left.1{ }^{\circ} \mathrm{C} / \mathrm{s}\right)$ and sub-step $2\left(60{ }^{\circ} \mathrm{C}\right.$ for $1 \mathrm{~min}$, then rapid heating to $95{ }^{\circ} \mathrm{C}$ with $1{ }^{\circ} \mathrm{C} / \mathrm{s}$ ). A threshold quantification cycle $\left(\mathrm{C}_{\mathrm{q}}\right)$ was evaluated for each gene using the manufacturer's software. Stability of reference gene expression, sample integrity, and differentially regulated target genes were calculated using the BestKeeper-algorithm, an Excel-based tool using pairwise correlations [9]. Relative target gene expression was finally calculated as $2^{\wedge}-\Delta \mathrm{C}_{\mathrm{q}}$, with $\Delta \mathrm{C}_{\mathrm{q}}$ being the difference between reference median and target gene $\mathrm{C}_{\mathrm{q}}$ value.

\section{Statistics}

Data were analyzed for normality and for homogeneous variances (Levene). In case of Gaussian distributions, ANOVA was employed. In case of heterogeneous variances and/or non-Gaussian distribution, a Kruskal-Wallis 
test was used. $P$ values $<0.05$ were regarded as statistically significant. Data are presented as mean \pm SEM for gene expression and mean \pm SD for capillary and cell counts.

\section{Results}

At 3 months of age, male obese animals had developed stable hyperglycemia $(20.7 \pm 1.3 \mathrm{mmol} / \mathrm{L}$ plasma glucose vs. $6.5 \pm 0.1 \mathrm{mmol} / \mathrm{L}$ in lean; $P$ ), which remained on this plateau for the remaining 5 months of observation (Table 1). Hyperinsulinemia initially present in obese rats at 2 months $(10.5 \pm 0.7 \mu \mathrm{g} / \mathrm{L}$ plasma insulin vs $0.2 \pm 0.04 \mu \mathrm{g} / \mathrm{L}$ in lean) decreased due to $B$-cell insufficiency at 3 months (3.9 \pm 0.6 vs. $0.5 \pm 0.09 \mu \mathrm{g} / \mathrm{ml}$ in lean).

Retinal morphology assessed at 8 months of age revealed an increase in the number of $\mathrm{AC}$ in obese $\left(24 \pm 5 / \mathrm{mm}^{2}\right)$ versus lean $\mathrm{ZDF}$ rats $\left(15 \pm 4 / \mathrm{mm}^{2}\right.$, Fig. 1; Table 1). Pericyte number was reduced by $28 \%$ in obese $(1,618 \pm 241 /$ $\left.\mathrm{mm}^{2}\right)$ versus lean animals $\left(2,238 \pm 309 / \mathrm{mm}^{2}\right)$, and endothelial cell counts significantly increased by $16 \%$ $\left(3,800 \pm 438 / \mathrm{mm}^{2}\right.$ in obese vs. 3,266 $\pm 415 / \mathrm{mm}^{2}$ in lean $)$.

VEGFa, MIF, and HIF-1 $\alpha$ were the most abundantly expressed genes in retinas from both obese and lean ZDF rats, but not differentially regulated (Fig. 2). bFGF (FGF2) and placental growth factor (PGF) were significantly expressed and up-regulated in diabetic animals $(5.4 \mathrm{X}$ for bFGF and 2.6X for PGF). Specific adhesion molecules, ITGAM, ITGB2, and ICAM1, were found to be significantly up-regulated in the diabetic environment. Nearly all inflammatory genes in our set were either not expressed or expressed at very low abundance. A significant up-regulation on a very low expression level could be observed for Il-1ß, but not for TNFa and IL-6.

Table 1 Hyperglycemia, hyperinsulinemia and selected retinal parameters determined in the course of the study

\begin{tabular}{|c|c|c|c|c|c|c|}
\hline \multirow{2}{*}{$\begin{array}{l}\text { Age } \\
\text { Biomarker }\end{array}$} & \multicolumn{2}{|l|}{2 months } & \multicolumn{2}{|l|}{3 months } & \multicolumn{2}{|l|}{8 months } \\
\hline & Lean ZDF & Obese ZDF & Lean ZDF & Obese ZDF & Lean ZDF & Obese ZDF \\
\hline Blood glucose $(\mathrm{mmol} / \mathrm{L})$ & $6.5 \pm 0.1$ & $13.6 \pm 1.3$ & $6.8 \pm 0.1$ & $20.7 \pm 1.3$ & $6.7 \pm 0.1$ & $22.4 \pm 0.7$ \\
\hline Plasma insulin $(\mu \mathrm{g} / \mathrm{L})$ & $0.2 \pm 0.04$ & $10.5 \pm 0.7$ & $0.5 \pm 0.09$ & $3.9 \pm 0.6$ & $3.4 \pm 0.2$ & $3.8 \pm 0.2$ \\
\hline Number of retinal acellular capillaries $\left(\mathrm{mm}^{-2}\right)$ & n.d. & n.d. & n.d. & n.d. & $15 \pm 4$ & $24 \pm 5$ \\
\hline Number of retinal endothelial cells $\left(\mathrm{mm}^{-2}\right)$ & n.d. & n.d & n.d. & n.d. & $3,266 \pm 415$ & $3,800 \pm 438$ \\
\hline Number of retinal pericyte cells $\left(\mathrm{mm}^{-2}\right)$ & n.d. & n.d. & n.d. & n.d. & $2,238 \pm 309$ & $1,618 \pm 241$ \\
\hline
\end{tabular}

A

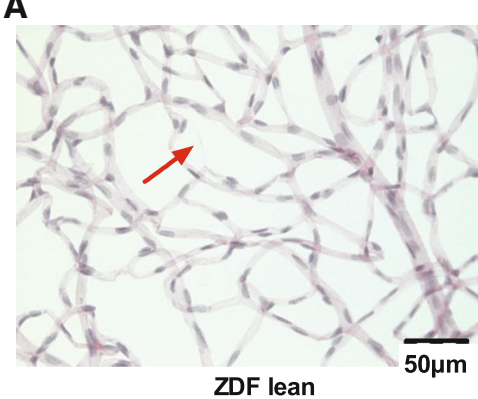

C

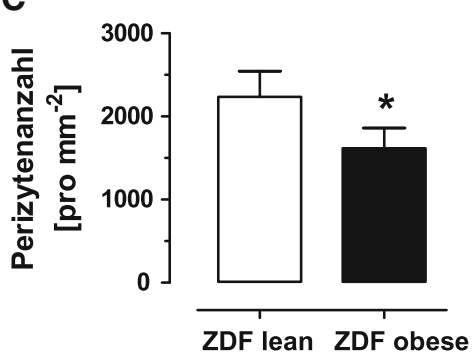

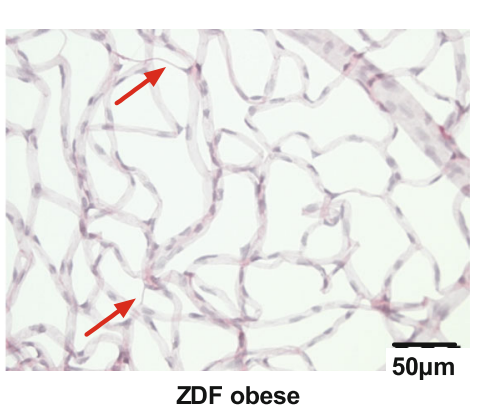

D

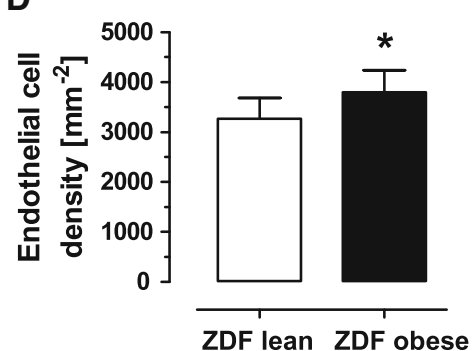

B

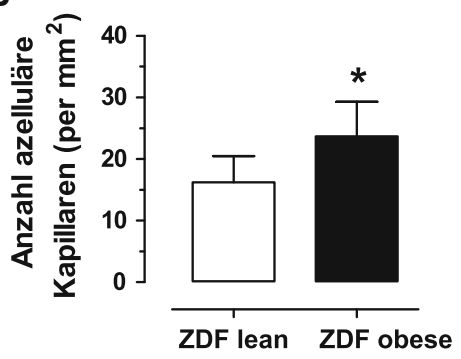

E

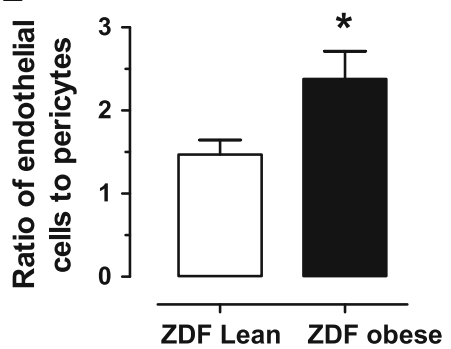

Fig. 1 Morphological changes in retina from aged male obese type-2 diabetic ZDF rats. a Representative PAS-stained retinas of lean and obese ZDF rats. Red arrows point to AC. b Quantitative assessment of
AC. c and d. Count in pericytes and endothelial cells. E. Ratio of endothelial cell to pericyte numbers. Asterisk denotes $P<0.05$ (color figure online) 

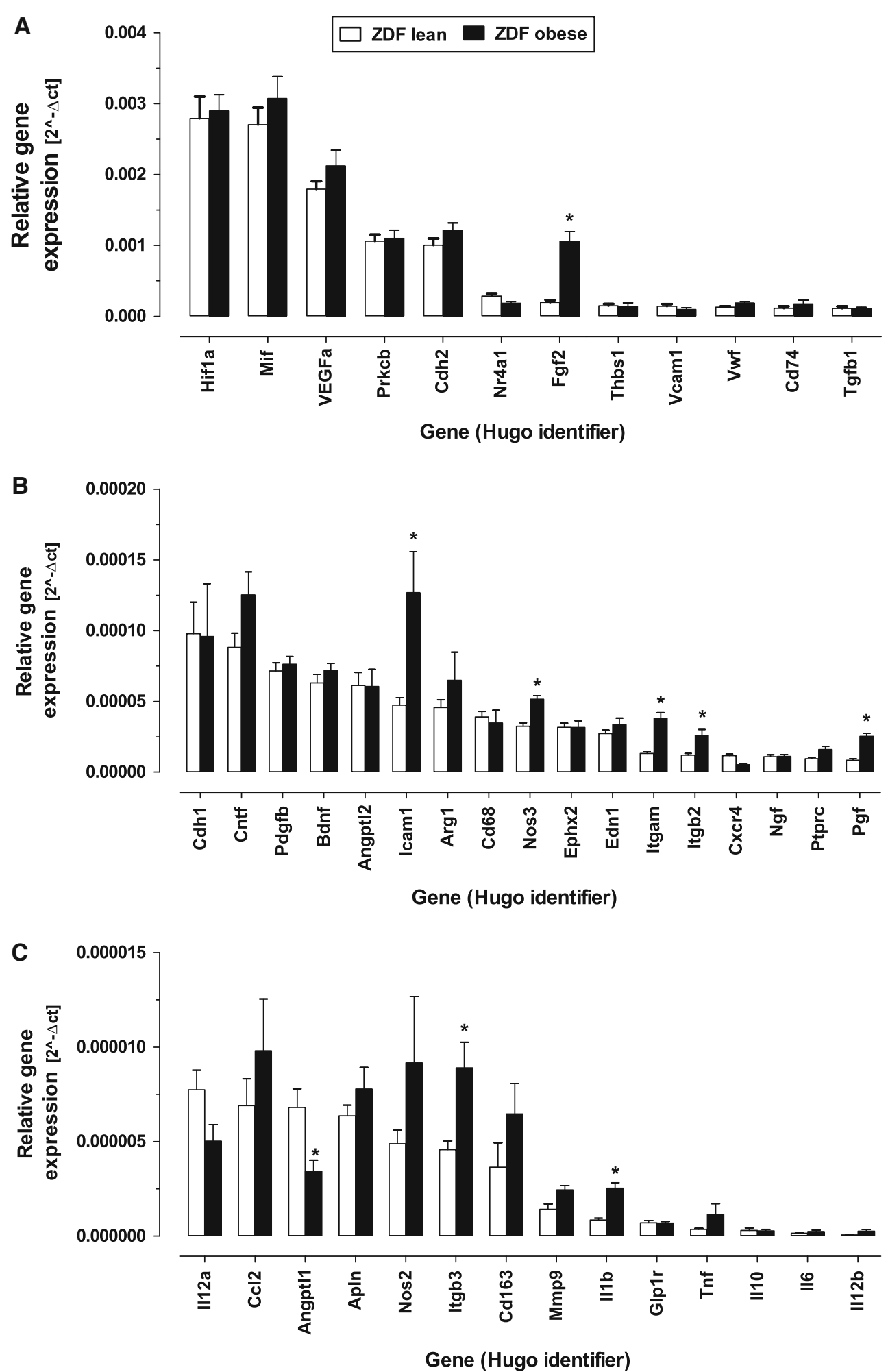

Fig. 2 Quantitative assessment of gene expression by microfluidic card PCR. Relative expression to the geometric mean of three housekeeping genes is given and categorized into high (a), medium (b), and low abundant (c) expression. Asterisk denotes $P<0.05$ 


\section{Discussion}

Our study shows that in a rat model of type- 2 diabetes, retinal vasoregression associated with regulations in specific growth factors and adhesion molecules as reflected by a quantitative gene expression protocol.

Strength of microfluidic card PCR technology is that gene expression of a broader number of genes can be rapidly quantified and compared with very high accuracy. As a limitation, not all known genes can be assessed in an unbiased manner, and hence, the pre-selection of genes to be investigated is of utmost importance. We therefore focused on genes, which have been described so far in several models of diabetic retinopathy and compared quantitatively their relative contribution in type-2-like diabetic retinopathy.

In line with Behl et al. [4], we observed in aged male obese ZDF rats an increased number of acellular retinal capillaries and a pericyte dropout. These morphological changes were similar to changes observed in type-1 diabetes models [10]. Among the investigated genes, only a few are differentially regulated but those may hint to important underlying molecular mechanisms.

Inflammatory genes such as TNF $\alpha$, interleukin- $1 \beta$, and inducible nitric oxide synthase were found to be expressed at a low abundant level, supporting the view of a low-grade inflammatory component. The simultaneous up-regulation of the ITGAM/ITGB2 complex and ICAM-1 provides evidence to an increased leukocyte recruitment process [11]. As noted recently, these entrapped leukocytes may directly damage retinal endothelial cells. However, the overall contribution of leukostasis to retinal disease progression is questionable, since vasoregression can be prevented by different treatment options without significant reduction in leukostasis $[12,13]$.

High abundant expression was observed for all growth factors investigated, but differential expression between type-2 diabetic and non-diabetic animals could be observed only for bFGF and PGF. Basic fibroblast growth factor (FGF2) is constitutively expressed in the retina, and its expression is increased by a microlesions but the role in preclinical models of retinal vascularization is still uncertain [14]. In clinical diabetic retinopathy, the normal retinal distribution of bFGF changed during the development of diabetic retinopathy and correlated with the onset of retinal neovascularization [15]. bFGF was also involved in repair of laser-induced retinal cell damage, suggesting that bFGF represents, at least in part, a survival factor for damaged neuroglial cells. Activity of PGF in diabetic retinopathy is characterized marginally. Viral-mediated over-expression of PGF in non-diabetic and diabetic rat retinas resulted in a similar up-regulation as observed in our study and contributed to capillary changes and blood-retinal barrier breakdown [16].

Within our selection of genes, VEGF was the growth factor with the highest expression but no significant differential regulation. Others had demonstrated that VEGF mRNA and protein expression is increased in retinae of obese versus lean ZDF rats, albeit at younger disease age and with only a modest up-regulation [6]. In our study, the baseline expression of differentially regulated growth factors such as bFGF and PGF was 550X and 22X higher compared to TNFa. Although this does not rule out any role of low-grade inflammation in the disease progression, it clearly demonstrates that future work should also focus again on specific growth factors, bFGF and PGF, and their contribution as pathological but also survival factors within the retinal neurovascular units.

Even though the insulin level is close to be similar in the diabetic versus non-diabetic rats at 8 months of age, the number of AC and pericyte loss are significantly different as is the blood glucose level. This is in accordance with previous findings that glucose, but not insulin, may determine the biochemistry of microvascular damage (for a review, see [17]). Furthermore, differences in pericyte loss and vasoregression are more likely a consequence of altered glucose-driven pathways than of insulin signaling alterations [18]. It may be interesting to compare retinal vasoregression in ZDF rats versus Zucker fatty rats (ZF rats), which displays persistently high levels of insulin but no hyperglycemia. If vasoregression indeed cannot be identified in ZF rats, this would finally support the role of hyperglycemia as initiating factor.

The finding that not VEGF but bFGF predominates in the diabetic retina at this time point may be indicative of a differential response to injury, combining the tissue response to biochemical stress and the patterning of growth factor expressions in various cells of the retina. Although both VEGF and bFGF are predominantly expressed by Müller cells, the temporal expression may vary. Further studies including earlier time points may be helpful to unravel differences in temporal expression patterns of VEGF, bFGF, and PGF.

In summary, our study identified a strong expression gradient of different genes involved in the pathogenesis of diabetic retinopathy. Most of the inflammatory markers were found at the low end of expression. Given this interesting molecular patterning and reliable morphological changes, we confirmed that male obese ZDF rats are suitable preclinical model for testing new therapeutic approaches in diabetic retinopathy.

Acknowledgments We acknowledge the assistance of Adrienne Pall and Valerie Faltermann in performing the microfluidic card PCR 
analysis. This work was supported by a research grant provided by Sanofi to HPH.

Conflict of interest Jihong Lin, Nadine Dietrich, and Hans-Peter Hammes have nothing to disclose. P. Wohlfart, A. Kannt, R. Elvert, and A. W. Herling are full research employees of Sanofi and involved in identification and validation of new therapeutic approaches in diabetes.

Human and Animal rights All institutional and national guidelines for the care and use of laboratory animals were followed. No human studies were carried out by the authors for this article.

Open Access This article is distributed under the terms of the Creative Commons Attribution License which permits any use, distribution, and reproduction in any medium, provided the original author(s) and the source are credited.

\section{References}

1. Hirsch IB, Brownlee M (2010) Beyond hemoglobin A1c-Need for additional markers of risk for diabetic microvascular complications. JAMA 303:2291-2292

2. Danis RP, Yang Y (1993) Microvascular retinopathy in the Zucker diabetic fatty rat. Invest Ophthalmol Vis Sci 34:2367-2371

3. Yang YS, Danis RP, Peterson RG, Dolan PL, Wu YQ (2000) Acarbose partially inhibits microvascular retinopathy in the Zucker diabetic fatty rat (ZDF/Gmi-fa). J Ocul Pharmacol Ther 16:471-479

4. Behl Y, Krothapalli P, Desta T, DiPiazza A, Roy S, Graves DT (2008) Diabetes-enhanced tumor necrosis factor-alpha production promotes apoptosis and the loss of retinal microvascular cells in type 1 and type 2 models of diabetic retinopathy. Am J Pathol 172:1411-1418

5. Behl Y, Krothapalli P, Desta T, Roy S, Graves DT (2009) FOXO1 plays an important role in enhanced microvascular cell apoptosis and microvascular cell loss in type 1 and type 2 diabetic rats. Diabetes 58:917-925

6. Mima A, Qi W, Hiraoka-Yamomoto J et al (2012) Retinal not systemic oxidative and inflammatory stress correlated with VEGF expression in rodent models of insulin resistance and diabetes. Invest Ophthalmol Vis Sci 53:8424-8432

7. Miranville A, Herling AW, Biemer-Daub G, Voss MD (2012) Differential adipose tissue inflammatory state in obese nondiabetic Zucker fatty rats compared to obese diabetic zucker diabetic fatty rats. Horm Metab Res 44:273-278

8. Dietrich N, Hammes HP (2012) Retinal digest preparation: a method to study diabetic retinopathy. Methods Mol Biol 933:291-302

9. Pfaffl MW, Tichopad A, Prgomet C, Neuvians TP (2004) Determination of stable housekeeping genes, differentially regulated target genes and sample integrity: BestKeeper-Excelbased tool using pair-wise correlations. Biotechnol Lett 26:509-515

10. Hammes HP, Martin S, Federlin K, Geisen K, Brownlee M (1991) Aminoguanidine treatment inhibits the development of experimental diabetic retinopathy. Proc Natl Acad Sci USA $88: 11555-11558$

11. Noda K, Nakao S, Ishida S, Ishibashi T (2012) Leukocyte adhesion molecules in diabetic retinopathy. J Ophthalmol 2012:279037

12. Li G, Tang J, Du Y, Lee CA, Kern TS (2011) Beneficial effects of a novel RAGE inhibitor on early diabetic retinopathy and tactile allodynia. Mol Vis 17:3156-3165

13. Wang Q, Gorbey S, Pfister F et al (2011) Long-term treatment with suberythropoietic Epo is vaso- and neuroprotective in experimental diabetic retinopathy. Cell Physiol Biochem 27:769-782

14. Ozaki H, Okamoto N, Ortega S et al (1998) Basic fibroblast growth factor is neither necessary nor sufficient for the development of retinal neovascularization. Am J Pathol 153:757-765

15. Hanneken A, de Juan E, Lutty GA Jr, Fox GM, Schiffer S, Hjelmeland LM (1991) Altered distribution of basic fibroblast growth factor in diabetic retinopathy. Arch Ophthalmol 109:1005-1011

16. Kowalczuk L, Touchard E, Omri S et al (2011) Placental growth factor contributes to micro-vascular abnormalization and bloodretinal barrier breakdown in diabetic retinopathy. PLoS One 6:e17462

17. Giacco F, Brownlee M (2010) Oxidative stress and diabetic complications. Circ Res 107:1058-1070

18. Pfister F, Feng Y, vom Hagen F et al (2008) Pericyte migration: a novel mechanism of pericyte loss in experimental diabetic retinopathy. Diabetes 57:2495-2502 